\title{
Extracción de $\mathrm{ADN}$ humano mediante dos métodos para la tipificación forense a partir de muestras fecales en papel FTA
}

\author{
Human DNA Extraction by Two Extraction Methods for \\ Forensic Typification from Human Feces on FTA Paper
}

Shirleny Monserrat Sandoval-Arias'

Fecha de recepción: 19 de marzo del 2014

Fecha de aprobación: 28 de mayo del 2014

Sandoval-Arias, S. Extracción de ADN humano mediante dos métodos para la tipificación forense a partir de muestras fecales en papel FTA. Tecnología en Marcha. Vol. 27, N 4, Octubre-Diciembre. Pág |4-2|. 


\section{Palabras clave}

Tipificación forense; heces humanas; DNA IQTM Casework Sample Kit para Maxwell @ I6; extracción orgánica.

\section{Resumen}

La identificación de sospechosos en casos criminales se ha facilitado desde la aplicación de pruebas de ADN a diferentes muestras. El uso de esta técnica para la tipificación forense a partir de muestras fecales humanas aún presenta complicaciones, por lo que en esta investigación se evaluaron dos protocolos de extracción de ADN con ciertas modificaciones para determinar el de mayor efectividad. Se realizaron extracciones orgánicas y mediante el kit comercial "DNA IQTM Casework Sample Kit para Maxwell ¿I6" a trozos de $4 \mathrm{~cm}^{2}$ y I $\mathrm{cm}^{2}$ de papel FTA impregnado con heces de un mismo individuo. En todos los casos se obtuvieron resultados útiles. Sin embargo, la tipificación forense óptima (dadas las características del electroferograma) se logró al utilizar el kit comercial en un área de papel FTA impregnado de $1 \mathrm{~cm}^{2}$ en dilución |:4.

\section{Key words}

Forensic Human typification; human feces; DNA IQTM Casework Sample Kit for Maxwell @I6; organic extraction.

\section{Abstract}

The identification of suspects in criminal investigations has been facilitated since DNA test are executed on different samples. The application of this technology for forensic typification from human fecal samples still presents complications therefore this research evaluated two DNA extraction protocols with modifications to determine that of major efficiency. Organic extractions and extractions using the commercial kit "IQTM DNA Casework Sample Kit for Maxwell ${ }^{\circledR}$ 16" on FTA portions of $4 \mathrm{~cm}^{2}$ and $1 \mathrm{~cm}^{2}$ impregnated with feces from the same individual were done to accomplish the objective. In all the assays the results were useful, however; the best forensic typification (by the electropherogram characteristics) was obtained by using the commercial kit in an area of $\mathrm{I} \mathrm{cm}^{2}$ of FTA paper impregnated in a 1:4 dilution.

\section{Introducción}

Las ciencias forenses proporcionan la ventaja de utilizar una de las herramientas más discriminatorias y fiables del sistema forense: la identificación humana mediante la tipificación de ADN a partir de muestras biológicas. Esta es una herramienta que ha cobrado gran importancia en el ámbito de administración de la justicia en los últimos años (Lorente, Vega y Rosas, 2007). Gracias a la identificación genética se logra una correlación individuo-prueba que, unida a otras evidencias, permite al sistema judicial determinar las consecuencias sociales y/o jurídicas a las cuales el presunto sospechoso debe someterse (Condori y Luna, 2007).

En un escenario criminal se puede encontrar una variedad de muestras biológicas, entre ellas están los restos tisulares, sangre, muestras pilosas, fluidos (semen, sudor, saliva, entre otros) y, aunque menos frecuente, materia fecal (Krude, 2008).
Las muestras fecales en análisis forenses han cobrado auge como una opción de evidencia en los últimos años, a pesar de que objetivamente son complicadas para la tipificación forense. Debido a la naturaleza propia de la muestra, existe la posibilidad de encontrar una serie de sustancias y microorganismos que pueden comprometer la integridad del ADN. Algunos de los posibles factores que afectan las condiciones de la muestra son la presencia de microorganismos, comida digerida y no digerida, mucosidad, productos solubles y no solubles del tracto intestinal y enzimas liberadas por las células y bacterias (Condori y Luna, 2007).

Aunado a ello, las muestras pueden degradarse por efectos ambientales $y / o$ presencia de bacterias (ajenas al tracto intestinal), lo que afectaría los análisis moleculares (Butler, 20 12; lacovacci, Serafini, Berti y Lago, 2003); además de sustancias como bilirrubina y sales biliares (presentes en las heces), posibles 
inhibidores de la reacción en cadena de la polimerasa (PCR) (Condori y Luna, 2007).

La extracción de ADN de las diversas muestras (incluyendo las fecales) puede realizarse mediante diferentes protocolos. Sin embargo, destaca la extracción orgánica (también conocida como extracción fenol-cloroformo) y la utilización de kits comerciales (Lutz y Bornscheuer, 2009). La extracción con fenol-cloroformo era la metodología más popular (Butler, 2005; Kieleczawa, 2006), sin embargo, con el paso de los años y las nuevas investigaciones se han diseñado kits que realizan las extracciones de ADN de mayor calidad en un menor tiempo. Además, la extracción orgánica tiene algunas características en contra, como su duración (de uno a tres días según el tejido o protocolo), consta de una cantidad significativa de pasos que aumentan la posibilidad de error y contaminación de las muestras (Butler, 2012). Sumado a ello, esta metodología puede aislar inhibidores de PCR junto con el ADN (Kieleczawa, 2006) y se requiere el uso de sustancias peligrosas para la salud del analista al efectuar la extracción (Butler, 2005).

Por otro lado, los kits comerciales varían en las metodologías mediante las cuales se extrae finalmente el ADN. Sin embargo, existen algunas ventajas con respecto a la extracción orgánica, porque generalmente permiten la obtención de ADN de alta calidad (Kieleczawa, 2006) al evitar la mayoría de los factores negativos mencionados sobre la extracción orgánica (Butler, 20I2). Pese a ello, tienen la desventaja de que pueden ser más costosos por muestra que otros protocolos no comerciales (Kieleczawa, 2006).

La tipificación forense mediante la extracción de ADN humano de muestras fecales se da debido a que diariamente son expulsadas 10,000 millones de células del tracto intestinal, según estudios de lacovacci, Serafini, Berti y Lago (2003), por lo que se esperaría tener suficiente material genético con el cual realizar los análisis. Pese a lo anterior, los protocolos de extracción y tipificación de ADN humano en muestras fecales son escasos y en la mayoría de los ensayos la literatura no reporta resultados positivos (lacovacci et al., 2003). Dado que Costa Rica no está exenta de esta problemática y en los últimos años ha aumentado dicha evidencia, este proyecto pretende establecer una metodología viable de extracción de ADN humano de muestras fecales para la tipificación forense, evaluando un método de extracción convencional (extracción orgánica) y un kit comercial.

\section{Material y método}

Los procesos de extracción de ADN y de análisis genético se realizaron en la Sección de Bioquímica, Unidad de Genética Forense del Complejo de Ciencias Forenses, y en el Laboratorio de la Dra. Sandra Silva de la Fuente.

\section{Manejo de la muestra}

La muestra fresca se recolectó de un individuo adulto de sexo masculino. Se colocó en un envase plástico estéril con tapa de rosca. En un plazo no superior a las 24 horas se impregnó una pequeña cantidad de heces en papel FTA, el cual se colocó en una cámara de flujo y se dejó secar. Posteriormente, se almacenó a $-20^{\circ} \mathrm{C}\left( \pm 3^{\circ} \mathrm{C}\right)$.

\section{Extracción del ADN}

Se empleó la extracción orgánica de lacovacci y colaboradores (2003) y el DNA IQTM Casework Sample Kit para Maxwell @I6 (Krnajski, Geering y Steadman, 2007); ambos protocolos modificados y en porciones de papel FTA de $1 \mathrm{~cm}^{2}$ y $4 \mathrm{~cm}^{2}$ para cada uno.

\section{a) Extracción de lacovacci y colaboradores (2003) modificada}

Se recortó un trozo de papel impregnado de muestra de $1 \mathrm{~cm}^{2}(A)$ y $4 \mathrm{~cm}^{2}(B)$. Cada área se recortó en trozos pequeños y se colocó en tubos de microcentrífuga, se digirieron en agitación ( 800 rpm en shaker) a $37^{\circ} \mathrm{C}$ durante $12 \mathrm{~h}$ en $500 \mu \mathrm{l}$ de buffer de extracción ( $10 \mathrm{mM}$ Tris- $\mathrm{HCl} \mathrm{pH} 8,100 \mathrm{mM} \mathrm{NaCl}$, I0mM EDTA, 2\%SDS, 39 mM Ditiotreitol (DTT)) con $15 \mu$ l de proteinasa $K(20 \mathrm{mg} / \mathrm{ml})$. El ADN se extrajo mediante la técnica de fenol-cloroformo. El ADN se purificó con columnas Milliporo Microcon TM o R, poro YM- I00 y se resuspendió en $50 \mu \mathrm{l}$ de $\mathrm{H}_{2} \mathrm{O}$ des-ionizada.

\section{b) Extracción con DNA IQTM Casework Sample Kit para Maxwell $®$ /6}

Lisis de la muestra: Se agregó 320ul de DTT IM a una botella completa de buffer de lisis del DNA IQ ${ }^{\mathrm{TM}}$ Casework Sample Kit para Maxwell囚I6 y se agitó 
por inversión. Se tomaron cuadrados de $1 \mathrm{~cm}^{2}$ (C) y $4 \mathrm{~cm}^{2}$ (D) de papel FTA impregnado con heces; cada trozo se recortó en pequeños fragmentos y se colocaron en tubos de microcentrífuga.

Se agregó $500 \mu \mathrm{l}$ de buffer de lisis con DTT, se incubó por 30 minutos a $95^{\circ} \mathrm{C}$ en baño María, se centrifugó a 1400 rpm durante 4 minutos, se recolectó el sobrenadante y se realizó la extracción de ADN automatizada con el Maxwell.

Extracción de ADN automatizada con el Maxwel/囚 / 6: Se realizó el procedimiento especificado por el fabricante y se almacenó el ADN extraído en refrigeración $\left(4\right.$ a $\left.8^{\circ} \mathrm{C}\right)$.

\section{Cuantificación del ADN}

Se utilizó el Kit Quantifiler Human (Applied Biosystems, USA) y el equipo 7500 PCR Real Time (Applied Biosystems, USA) con el Time 7500 System SDS Software (Applied Biosystems, USA). Se agregó un control positivo $(5 \mu l$ de ADN del Kit de cuantificación) y un control negativo.

\section{Amplificación de marcadores moleculares}

Se utilizó el Kit PowerPlex ${ }^{R}$ I6HS (Promega, USA); éste amplifica los marcadores D3SI358, THOI, D2ISII, DI8S5I, Penta E, D5S8I8, DI3S317, D7S820, DI6S539, CSFIP0, Penta D, amelogenina, vWA, D8SII79, TPOX y FGA.

El ADN extraído de los tratamientos A) y B) se trabajó sin diluir y con dilución $1: 2, C$ ) en dilución I:4 y D) sin diluir; todas en volumen de reacción completa. Se agregó un control positivo y un control negativo de PCR.

\section{Resultados}

A: Extracción de lacovacci y colaboradores (2003) modificada con área de $1 \mathrm{~cm}^{2}$. B: Extracción de lacovacci y colaboradores (2003) modificada con área de $4 \mathrm{~cm}^{2}$. C: Extracción con DNA IQTM Casework Sample Kit para Maxwell $® 16$ áerea de $1 \mathrm{~cm}^{2}$. D: Extracción con DNA IQTM Casework Sample Kit para Maxwell @16 áerea de $4 \mathrm{~cm}^{2}$

En el cuadro I se muestran los resultados de la cuantificación de ADN de las extracciones A), B), C) y D). Todas las muestras presentan una cantidad de ADN superior al mínimo valor determinado para la amplificación según las especificaciones del comerciante, así como la ausencia de inhibidores que puedan comprometer la amplificación.

Las muestras A y B presentan una cantidad de ADN que aproximadamente triplica y duplica (respectivamente) el rango superior necesario para la amplificación de los marcadores utilizados según el comerciante. La muestra C es aproximadamente II veces mayor al rango superior anteriormente mencionado $y$, por el contrario, la muestra $D$ se encuentra en el límite del rango mínimo para la amplificación según las especificaciones del comerciante.

El Kit PowerPlex ${ }^{R}$ I6HS (Promega, USA) amplificó los 15 marcadores en todos los casos; sin embargo, se obtuvieron electroferogramas con mejor caracterización de los marcadores en la muestra C, en dilución 1:4 (figura 1), lo que permitió la identificación del individuo a través de la tipificación forense.

Cuadro I. Cuantificación de ADN de las extracciones A), B), C) y D)

\begin{tabular}{|c|c|c|}
\hline Muestras & $\begin{array}{c}\text { Cuantificación } \\
(\mathrm{ng} / \mu \mathrm{l})\end{array}$ & Inhibidores \\
\hline A & 0,412 & No presenta inhibidores \\
\hline B & 0,296 & No presenta inhibidores \\
\hline C & 1,45 & No presenta inhibidores \\
\hline D & 0,0455 & No inhibidores \\
\hline
\end{tabular}




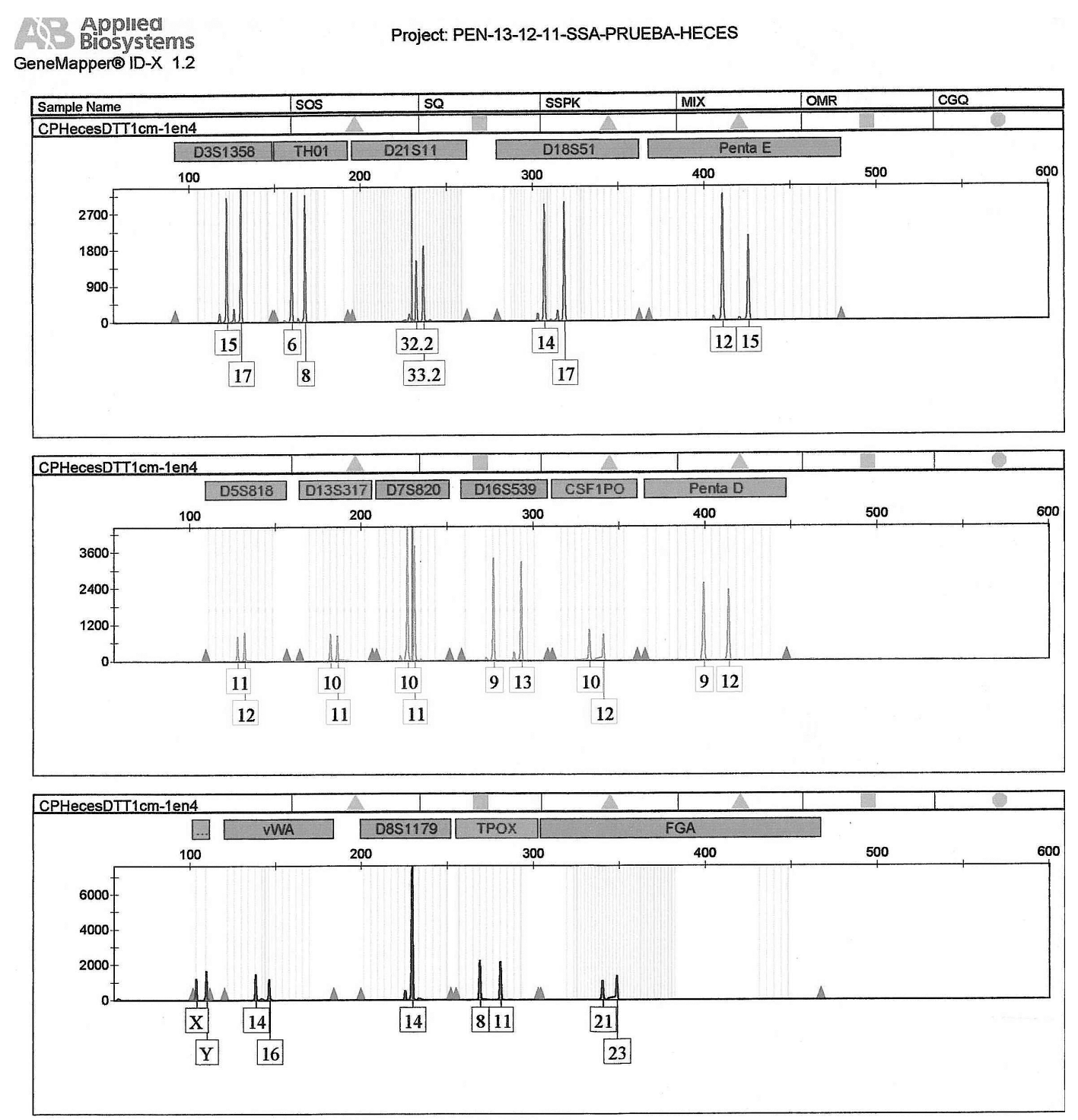

Figura I. Electroferograma del protocolo de extracción con IQTM casework Sample Kit para Maxwell @ I6 en área de $1 \mathrm{~cm}^{2}$ y dilución 1:4 (Muestra C).

\section{Discusión}

las muestras de hece se almacenaron en papel FTA (Flinders Technology Associates 7), el cual está constituido de una membrana de celulosa que contiene químicos capaces de inactivar un amplio rango de microorganismos preservando los ácidos nucleicos (Perozo, Villegas, Alvarado, Estévez, Rivera y Mavárez, 2006). El papel FTA permite un mejor manejo de las muestras y disminuye el riesgo de contaminación. No obstante, se debe tomar en cuenta la metodología de conservación de las muestras; a menor temperatura disminuye la actividad enzimática y metabólica microbiana, aminorando el riesgo de degradación del ADN (Frantzen, Silk, Ferguson, Wayne y Kohn, 1998).

Existen algunas diferencias entre las metodologías de lisis celular empleadas, entre las cuales se destaca el uso de DTT. Sin embargo, en una de ellas también se agregó proteinasa K. EI DTT utilizado en conjunto con el buffer de lisis actúa como un agente reductor y antioxidante capaz de romper puentes disulfuro, lo que permite la degradación de las membranas celulares. Este reactivo se utiliza principalmente para el análisis de muestras líquidas (Gonzáles, 2007), a diferencia de la proteinasa K, utilizada para muestras sólidas, en donde interacciona en la ruptura de enlaces peptídicos, permitiendo la degradación 
de las membranas celulares y proteínas presentes durante la extracción que pueden afectar el ADN (Van Waters-Rogers, 20 I I).

Dado que ambos protocolos utilizados presentaron resultados positivos, se plantea que la utilización de DTT podría ser más favorable en contraste con las metodologías en las que se aplica únicamente proteinasa K para la lisis celular.

Se logró obtener una cantidad idónea de ADN de alta calidad; mayor a $0,023 \mathrm{ng} / \mu \mathrm{l}$ en cuantificación (President's DNA Initiative, 2008), valor aún menor que el que se requiere para la amplificación de los diversos marcadores, ya que en este se necesita un mínimo de 0,05-0, I25ng/ $\mathrm{\mu l}$ de ADN en la solución final (Entrala, 2000), en contraposición a otras muestras y análisis no especificados en este estudio. Esto se debe a que la cantidad de células provenientes del tracto digestivo varía entre personas por los diferentes hábitos alimentarios, lo que implica mayor o menor cantidad de ADN extraíble, que en ocasiones puede no ser suficiente para realizar los análisis posteriores (lacovacci et al., 2003).

En las heces se puede desarrollar gran variedad de bacterias porque obtienen, a partir de las células excretadas, por la descamación intestinal, la energía para su crecimiento (Thompson, Maldonado y Gil, 2004). Sumado a lo anterior, el ADN humano presente en las muestras puede ser degradado por acción de enzimas como las ADNasas.

Por otro lado, el tiempo, la condición y la manipulación de las muestras aumentan la posibilidad de contaminación y degradación del material genético (Frantzen, Silk, Ferguson, Wayne y Kohn, 1998). Las personas que circulan en el lugar de toma de la muestra pueden interferir en el resultado final, pues se genera un flujo de aire que hace que los microorganismos precipitados se suspendan (Solano, 2008) y lleguen con mayor facilidad a éstas. Además, si el proceso de transporte hasta los laboratorios no es eficiente, se puede promover la degradación del ADN, comprometiendo así los resultados de la prueba e invalidando cualquier análisis realizado.

Otra variable por considerar es el lugar en donde se encuentran las muestras. Dependiendo de este, puede incrementarse el riesgo de contaminación microbiana, por lo que aumentaría la posibilidad de degradación del ADN. Además, debe considerarse la presencia o ausencia de inhibidores en el ADN extraído y purificado, según sea el caso, esta variable determina la posibilidad de que se dé o no la amplificación del ADN por PCR y por lo tanto la tipificación del individuo.

En ocasiones, la extracción con fenol-cloroformo no suele ser tan efectiva debido a que pueden quedar residuos de fenoles, dado que estos exhiben una solubilidad similar al ADN y por lo tanto no son removidos eficientemente durante el proceso de extracción. Por el contrario, los métodos comerciales permiten deshacerse de inhibidores de la PCR favoreciendo posteriormente el proceso de tipificación humana. Sumado a ello, la extracción orgánica es un procedimiento largo y tedioso que conlleva mucho más tiempo en relación con el procedimiento automatizado del Maxwell.

Respecto a la amplificación de los marcadores, el protocolo aplicado a la muestra $C$ en dilución 1:4 es el que presenta la concentración de ADN óptima para la amplificación y tipificación del individuo control. La dilución es recomendada debido a que la presencia de inhibidores en la muestra puede ser eliminada o disminuida al diluir el ADN extraído en $\mathrm{H} 2 \mathrm{O}$ o en $0.1 \mathrm{mmol}$ EDTA/Tris. Agregado a ello, una cantidad de ADN superior a la del resto de reactivos presentes en la amplificación produciría una serie de productos inespecíficos, picos fuera de escala y/o divididos, un desbalance entre locus, adenilación incompleta, así como un desperdicio de reactivos; y una dilución mayor produciría menor cantidad de ADN que impactaría creando desbalance de picos heterocigotos, decaimiento de alelos y desbalance entre locus (Butler, 2005).

\section{Amplificación de los marcadores utilizados}

La presencia de dos bandas en los resultados de la amplificación de amelogenina determina que el individuo es de sexo masculino, debido a que las señales representan el alelo $X$ y el alelo $Y$, y el peso molecular de cada uno, de 106bp y II2bp, respectivamente (Velarde, Molina, Solórzano, Cázarez, Rendón, Murillo y Ríos, 2008). La amelogenina es un marcador muy pequeño, por lo que aún en bajas concentraciones de ADN o con ADN parcialmente degradado, se puede dar su amplificación. De manera aislada, este resultado no tiene validez legal en un análisis forense, dado que la determinación del sexo no es prueba suficiente para incriminar a un individuo. 
En cuanto a los demás marcadores utilizados (Penta E, DI8S5I, D2ISII, THOI, D3SI358, FGA, TPOX, D8SI I79, vWA, Penta D, CSFIPO, DI6S539, D7S820, DI3S317, D5S8I8) del PowerPlex I6HS Kit (Ensenberger y Fulmer, 2009), se obtuvo de igual manera una amplificación positiva en todas las muestras. A pesar de ello, se sugiere utilizar el protocolo $C$ en dilución 1:4. Lo anterior surge al analizar los electroferogramas obtenidos para las metodologías utilizadas (figura I). Hay una serie de características que permiten identificar un adecuado electroferograma; algunas de ellas son: ausencia de artefactos (señales inespecíficas previas a las señales de cada marcador), el ancho y áreas de los picos debe ser similar (Cerow, 20l0), no deben aparecer señales hasta que se detecten las secuencias de los marcadores en cuestión, los picos deben iniciarse en un mismo punto base (0) y se deben observar las señales de todos los marcadores amplificados (Applied Biosystems, 2009). Las últimas dos características las comparten todos los electroferogramas pero el protocolo $\mathrm{C}$ en dilución 1:4 comparte las demás características mencionadas, lo cual lo convierte en el más adecuado. La afirmación anterior no implica que los demás resultados no sean útiles.

Pese los resultados de esta investigación, científicos como Frantzen, Silk, Ferguson, Wayne y Kohn (1998) indican que las muestras de heces humanas son muy complejas de tratar, incluso más complejas que las heces de otros animales. La literatura señala que aunque se han realizado varios estudios con diversos métodos, en la minoría de los casos se obtienen resultados positivos, ya que estas muestras se encuentran alteradas por sus propias condiciones, la recolección, la preservación, así como la influencia de factores ecológicos, de dieta y factores intraespecíficos del ADN, como la preservación y concentración de esta sustancia en cada muestra.

\section{Conclusiones}

La extracción de ADN humano a partir de heces humanas es un procedimiento afectado por diferentes factores, tales como la recolección, manipulación y el almacenamiento; además de que puede encontrarse en muy bajas cantidades y tener inhibidores que dificultan aún más el proceso para lograr la tipificación forense.
Las muestras deben ser sometidas a un correcto proceso de recolecta y preservación para evitar al máximo su degradación; paralelamente se recomienda ejecutar el procedimiento de extracción en el menor tiempo posible.

El mejor protocolo de extracción de ADN Humano para tipificación forense a partir de muestras fecales impregnadas en papel FTA corresponde, para este estudio en particular, y dada la cuantificación de ADN en las muestras, al protocolo de extracción de ADN automatizada con el Maxwell ${ }^{\circledR} 16$ en un área de $4 \mathrm{~cm}^{2}$ en dilución 1:4 cuando las muestras fecales están en condiciones óptimas.

\section{Agradecimientos}

Se agradece a la Unidad de Genética Forense del Complejo de Ciencias Forenses, Costa Rica; en especial a la Dra. Martha Espinoza, la Dra. Gladys Nuñez y la Dra. Magaly Segura, así como a la Dra. Sandra Silva y a la MSc. María Clara Soto, ya que sin su apoyo y paciencia este proyecto no se hubiera podido realizar.

\section{Bibliografía}

Applied Biosystems. (2009). DNA Sequencing by Capillary Electrophoresis. Applied Biosystems Chemistry Guide. 2 ed. California: Applied Biosystems.

Butler, J. M. (2005). Forensic DNA Typing: Biology, Technology, and Genetics of STR Markers. 2 ed. Massachusetts: Elsevier.

Butler, J. M. (2012). Advanced Topics in Forensic DNA Typing: Methodology. California: Elsevier.

Cerow, K. M. (20 I0). Peak Area versus Peak Height for Analysis of Forensically Relevant Short Tandem Repeats. (Master's Thesis). Boston University School of Medicine.

Condori, S. y Luna, G. (2007). Detección del marcador Y-STR de uso forense DYS393 en heces humanas. 2 ed.Visión Científica.

Ensenberger, M. y Fulmer, P. (2009). The PowerPlex® 16 HS System. USA: Promega Corporation.

Entrala, C. (2000). Técnicas de Análisis del ADN en Genética Forense. Laboratorio de ADN Forense [Internet]. Granada, España: Universidad de Granada, Departamento de Medicina Legal. Obtenido de http://www.ugr.es/ eianez/ Biotecnologia/forensetec.htm

Frantzen, M., Silk, J., Ferguson, J., Wayne, R. y Kohn, M. (1998). Empirical evaluation for preservation methods for faecal DNA. Molecular Ecology (1998), 7, | 423- 1428.

(Publicación en línea 28 febrero, 2002). 
Gonzáles, E. (2007). Papel de la Caveolas/Caveolina-I en la Fisiología del Adipocito. (Tesis PhD). Universidad de Barcelona.

lacovacci, I., Serafini, M., Berti, A. y Lago, G. (2003). STR typing for human faeces: a modified DNA extraction method. Elsevier Science.

Kieleczawa, J. (Ed.). (2006). DNA Sequencing II: Optimizing the Isolation, Preparation and Cleanup. Massachusetts: Jones \& Bartlett Publishers.

Krnajski, Z., Geering, S. y Steadman, S. (5 septiembre, 2007). Performance verification of the Maxwell 16 Instrument and DNA IQ Reference Sample Kit for automated DNA extraction of known reference samples. Forensic Sci Med Pathol., 3, 264-269.

Krude, T. (2008). ADN: Cambios en la ciencia y en la sociedad. AKAL.

Lorente, J.,Vega, M. y Rosas, G. (2007). Genética forense la ciencia al servicio de la justicia. Mensaje Bioquímico 31, 44-66.

Lutz, S. \& Bornscheuer, U. T. (Eds.). (2009). Protein Engineering Handbook. Weunheim: John Wiley \& Sons.

Perozo, F.,Villegas, P., Alvarado, I., Estévez, C., Rivera, S. y Mavárez,Y. (2006). Utilización de las Tarjetas FTA® para el Diagnóstico
Molecular del Virus de la Enfermedad de Newcastle en Muestras de Fluido Alantoideo. Rev. Cient., 16(2): I 18-123.

President's DNA Initiative. (2008). DNA Analyst Training. Laboratory Training Manual. Protocol 3.11. Quantifiler Quantitation Procedure [Internet]. Obtenido de http:// static.dna.gov/lab-manual/Linked\%20Documents/Protocols/ pdi_lab_pro_3.1 I.pdf

Solano, E. (2008). Metodología para la Validación del Equipo RCS High Flow para Monitoreo de Microorganismos en Aire Ambiental [Internet]. Instituto Tecnológico de Costa Rica. Obtenido de http://bibliodigital.itcr.ac.cr:8080/dspace/ bitstream/2238/562/I/Evelyn+Solano+Validaci\%EF\%BF \%BD\%EF\%BF\%BDn+RCS+High+Flow+Biblioteca.pdf

Thompson, O., Maldonado, J. y Gil, A. (2004). La microbiota intestinal en el niño y la influencia de la dieta sobre su composición. Alim. Nutri. Salud, I I (2), 37-48.

Van Waters-Rogers (WWA). (20II). Proteinasa K. Obtenido de https://es.vwr.com/app/Header?tmpl=/production/bio_ proteinase_k.htm

Velarde, J., Molina, C., Solórzano, R., Cázarez, S., Rendón, H., Murillo, J. y Ríos, J. (2008). Identificación del sexo mediante análisis molecular del gen de la amelogenina. Rev Mex Patol Clin., 55(I), 17-20. 